\title{
Heterogeneity of Plasma High Density Lipoproteins*
}

\author{
Robert I. Levy and Donald S. Fredrickson $\dagger$ \\ (From the Section on Molecular Disease, Laboratory of Metabolism, National Heart Institute,
} Bethesda, Md.)

The plasma high density lipoproteins, which are isolated between the densities 1.063 and 1.21 in the ultracentrifuge and which correspond to alpha $_{1}$ lipoproteins on electrophoresis, have been the subject of far fewer studies than their counterparts of lower density. In recent years, however, they have served as useful models for examination of lipoprotein structure and have become of particular interest to this laboratory since the discovery of Tangier disease, in which they are congenitally absent or seriously deficient (1).

When these lipoproteins are distributed along a density gradient, they seem to form a continuum without stepwise compositional changes (2). Subfractions isolated over different portions of the broad density band by which they are defined have been found to contain similar lipid composition and protein of the same amino acid composition (3). It is also usually accepted that the high density lipoproteins (HDL) are antigenically homogeneous $(4,5)$ and form a single electrophoretic band.

These data, however, have never been completely reconciled with other evidence that the high density lipoproteins may be discontinuously distributed over their common density band. For example, the separation of HDL into two major peaks in the analytical ultracentrifuge, a technique developed by deLalla and Gofman (6), is a reproducible phenomenon; it has been repeatedly demonstrated in different clinical situations that these fractions may independently vary in concentration (7). Preparative ultracentrifuge fractions corresponding to these two HDL peaks obtained in the analytical ultracentrifuge have also been found to contain protein moieties of quite different molecular weights (8). Subsequently, Shore (9) has presented evidence suggesting that HDL sub-

\footnotetext{
* Submitted for publication September 15, 1964 ; accepted November 27, 1964.

$\dagger$ Address requests for reprints to: Dr. D. S. Fredrickson, National Heart Institute, Bethesda, Md. 20014.
}

fractions may contain different multiples of a basic peptide, and this has since been partially confirmed by others $(10,11)$.

Finally, although only one major immunochemical study of high density lipoproteins (12) has concluded that they may be antigenically heterogeneous, there are other instances in which more than one form of this lipoprotein would appear to be present (13-16). Thus, there is both direct and indirect evidence of inhomogeneity among high density lipoproteins. The latter is of uncertain character and has required further definition. This is of particular importance in preparation of pure lipoprotein fractions required in current experimental work.

An intensive study of high density lipoproteins, with particular reference to their immunochemical identity, has therefore been undertaken. By using specific antisera to HDL, the lipoproteins present in plasma and ultracentrifugal fractions have been carefully characterized. It has been demonstrated that two forms of alpha lipoprotein exist (17). Their nature and relationship to certain transformations of the lipoproteins from their native state and the manner in which they help to reconcile discrepancies among older data are subjects of this report.

\section{Methods}

Unless otherwise indicated, blood was collected in $0.1 \%$ EDTA from normal males and females between ages 20 to $\mathbf{4 5}$ fasted overnight. Either individual plasma samples or that pooled from ten subjects was used. Analyses and fractionation were begun on the day of collection, and the remaining plasma was stored at $4^{\circ} \mathrm{C}$. In a few studies the low density lipoproteins (density $<1.063$ ) of fresh plasma were completely precipitated with $0.05 \mathrm{ml}$ per $\mathrm{ml} 0.1 \mathrm{M}$ manganese chloride and 2 mg per ml heparin in the cold (18), and the supernate was used as a source of alpha lipoprotein.

Preparative ultracentrifugation. Lipoprotein fractions were separated in the preparative ultracentrifuge by the method of Havel, Eder, and Bragdon (19). The density of plasma of lipoprotein isolates was raised by 
addition of $\mathrm{NaCl}$ and $\mathrm{KBr}$ (19) and checked by pyknometry at $20^{\circ} \mathrm{C}$. Samples were centrifuged at $10^{\circ} \mathrm{C}$ in the Spinco model $\mathrm{L}$ preparative ultracentrifuge at $40,000 \mathrm{rpm}$ (ca. $105,000 \mathrm{~g}$ ). With the no. 40.3 rotor, centrifugation was carried out for 16 hours at density 1.063 and 22 hours at densities 1.1 and 1.21. With the no. 40 rotor, the centrifuge times at comparable densities were 24 and 48 hours, respectively. As desired, one or more of four fractions were usually isolated. These are subsequently designated as LDL (density $<1.063$ ), $\mathrm{HDL}$ (density 1.063 to 1.21 ), $\mathrm{HDL}_{2}$ (density 1.063 to 1.1 ), $\mathrm{HDL}_{3}$ (density 1.1 to 1.21 ), and the fraction of density $>1.21$.

For use as antigen some LDL was prepared as the fraction of density 1.019 to 1.063 . The infranate of this material was not further used to prepare HDL.

The lusteroid tubes were sliced through the intermediate colorless zone with a standard tube slicer, and the top and bottom fractions were centrifuged once again at each separation density. This was done because of frequent immunochemical evidence of trace contamination of HDL by LDL and of HDL fractions by albumin and other nonlipoprotein proteins. After recentrifugation none of these contaminants was present in amounts detectable by immunoelectrophoresis or double diffusion studies except for trace amounts of LDL that could not be removed from the HDL fractions by as many as three recentrifugations. However, precipitation of LDL (18) before centrifugation eliminated all LDL contamination in subsequent HDL fractionation beginning with density 1.1. All fractions were dialyzed at $4^{\circ} \mathrm{C}$ against $40 \mathrm{vol}$ or more of $0.15 \mathrm{M} \mathrm{NaCl}$ containing
$0.01 \mathrm{M}$ EDTA at $\mathrm{pH} 6.5$ to 7.3. The dialysis fluid was changed three times during the 24-hour period.

Analytical ultracentrifugation. Lipoprotein fractions of densities 1.063 to 1.1 and 1.063 to 1.21 were centrifuged in the Spinco model $\mathrm{E}$ analytical ultracentrifuge within 24 hours of their preparation without dialysis. A double sector cell was employed, one side containing the 10 to $30 \mathrm{mg}$ per $\mathrm{ml}$ of lipoprotein, the other a solution of $\mathrm{NaCl}-\mathrm{KBr}$ of the same solvent density, providing the reference boundary. The rotor speed was 52,640 or $56,100 \mathrm{rpm}$ and the temperature $20^{\circ} \mathrm{C}$. The Schlieren patterns were photographed at intervals of 4 to $16 \mathrm{~min}$ utes for 2 to 3 hours at a bar angle of 65 to 70 .

In the analytical ultracentrifuge at density 1.21, HDL (density 1.063 to 1.21 ) appeared as an asymmetric single peak at 16 to 32 minutes. By 48 minutes it had resolved into at least two components (Figure 1). HDL2 (density 1.063 to 1.1 ) centrifuged at either solvent density of 1.1 or 1.21 appeared as a relatively homogeneous peak with a small tail of more slowly floating material apparent with time. 'In the analytical ultracentrifuge at density 1.1 $\mathrm{HDL}$ (density 1.063 to 1.21 ) separated by 32 minutes into two peaks. One was of an area equal to that previously determined for the $\mathrm{HDL}_{2}$ component; the other was a somewhat broader and sedimenting peak $\left(\mathrm{HDL}_{\mathrm{s}}\right)$. The Schlieren patterns were the same as those reported earlier by deLalla and Gofman (6), who introduced the nomenclature $\mathrm{HDL}_{2}$ and $\mathrm{HDL}_{3}$ to describe these major components of $\mathrm{HDL}$ distinguishable in the analytical ultracentrifuge. No small peak, comparable to their fraction $\operatorname{HDL}_{1}(6,7)$ was seen, probably because this lower density material

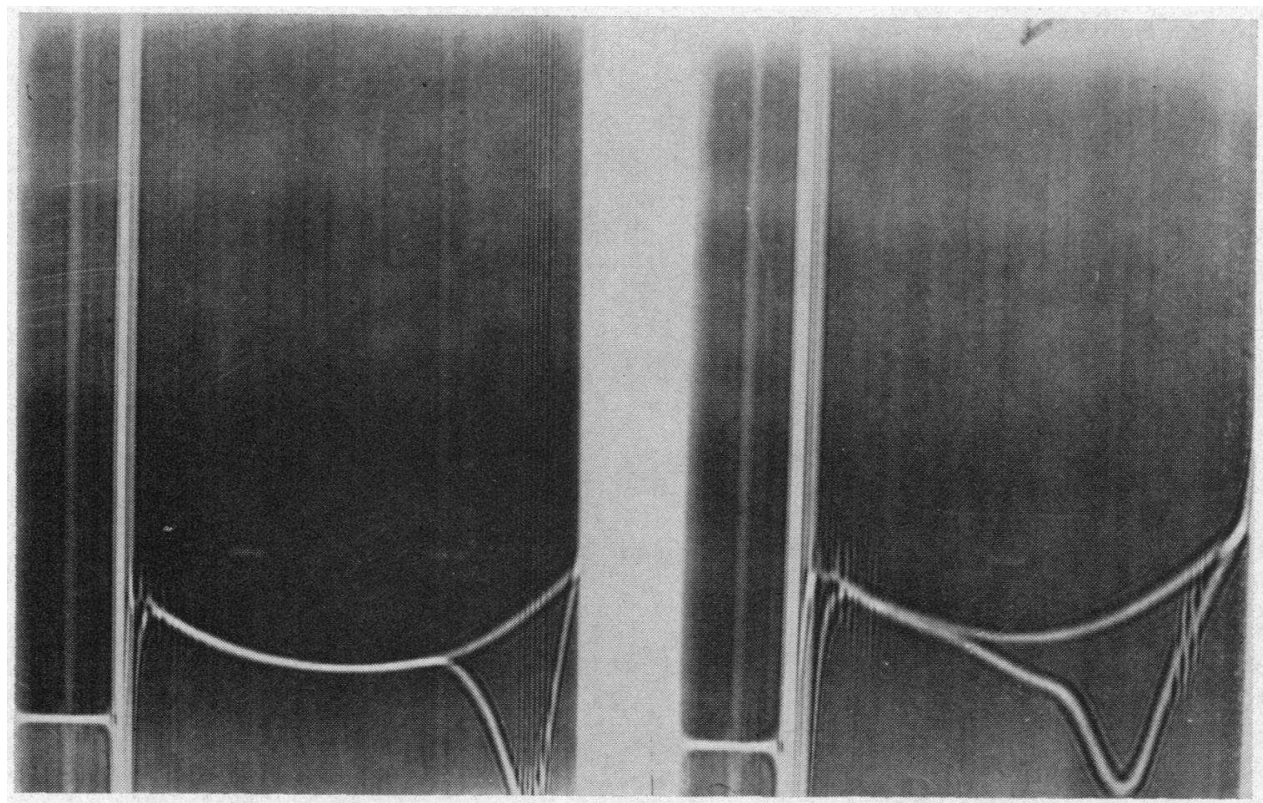

Fig. 1. Analytical ultracentrifugal analysis of high density lipoprotein (HDL) (D 1.063 то 1.21 ). Medium density $1.21,52,650 \mathrm{rpm}$, concentration $10 \mathrm{mg}$ of lipoprotein protein per $\mathrm{ml}, 26^{\circ} \mathrm{C}$. An asymmetric single peak can be seen at 30 minutes (left frame); a byphasic peak is apparent at 60 minutes (right frame). 
TABLE I

Lipid and alpha lipoprotein composition of plasma samples studied*

\begin{tabular}{|c|c|c|c|c|c|}
\hline & \multicolumn{2}{|c|}{ Plasma } & \multicolumn{3}{|c|}{ HDL } \\
\hline & Cholesterol & Phospholipid & Cholesterol & Phospholipid & Protein \\
\hline & \multicolumn{5}{|c|}{$m g$ per $100 \mathrm{ml}$} \\
\hline Pool A & 176 & 249 & 48 & 104 & 170 \\
\hline Subject 1 & 195 & 292 & 63 & 125 & 205 \\
\hline Subject 2 & 121 & 186 & 36 & 74 & 120 \\
\hline Subject 3 & 163 & 154 & 50 & 96 & 150 \\
\hline Subject 4 & 198 & 239 & 47 & 100 & 170 \\
\hline
\end{tabular}

* All high density lipoprotein (HDL) fractions reported above were obtained with the number 40 rotor.

had been removed by repeated preparative centrifugation at density 1.063 .

Lipid analysis. Two-ml samples of plasma lipoproteins were extracted in $50 \mathrm{ml}$ of chloroform: methanol $(2: 1)$, and the cholesterol (20) and phospholipid (21) contents determined. Protein was estimated by the method of Lowry, Rosebrough, Farr, and Randall (22). Representative examples of the total plasma lipid and HDL (density 1.063 to 1.21 ) lipid concentrations in the samples studied are given in Table I. $\mathrm{HDL}_{2}$ contained from 25 to $32 \%$ of the total HDL cholesterol and phospholipid, and 20 to $25 \%$ of the total HDL protein with the resulting average lipid to protein ratio of about 1.1 for $\mathrm{HDL}_{2}$ and 0.85 for $\mathrm{HDL}_{3}$. The fraction of density $>1.21$ contained less than $2 \mathrm{mg}$ per $100 \mathrm{ml}$ cholesterol and 10 to $20 \mathrm{mg}$ per $100 \mathrm{ml}$ of phospholipid, or 6 to $10 \%$ of the total plasma phospholipid.

Partial delipidation. Preparations of $\mathrm{HDL}_{2}$ and $\mathrm{HDL}_{3}$ were partially delipidated by injecting them through a no. 25 needle into $50 \mathrm{vol}$ of pure ethanol: ether $(3: 1)$ at $4^{\circ} \mathrm{C}$ for 24 hours. The resulting protein precipitate, containing 10 to $20 \%$ of the cholesterol and up to $50 \%$ of the phospholipid in the starting material, was then washed twice with 25 vol of cold redistilled diethyl ether. The washed precipitate readily redissolved in $0.15 \mathrm{M}$ $\mathrm{NaCl}$.

Immunochemical methods. Preparation of antisera. Antisera to LDL or HDL were prepared in both sheep and rabbits. Lipoprotein fractions used as antigens were mixed in an equal volume of complete Freund's adjuvant and injected intramuscularly. Some fractions were first concentrated 5- to 25-fold with Carbowax (15). The final protein concentration of the antigens was 20 to $50 \mathrm{mg}$ per $\mathrm{ml}$.

The total dose, administered in three divided doses at intervals of 3 weeks, was approximately $80 \mathrm{mg}$ of antigen protein to Cheviot sheep (wt. 40 to $50 \mathrm{~kg}$ ) and approximately $30 \mathrm{mg}$ to rabbits ( 3 to $5 \mathrm{~kg}$ ).

Antigen was stored at $4^{\circ} \mathrm{C}$ and prepared in adjuvant just before injection. Blood was collected 1 week after

TABLE II

Characterization of antisera used for immunochemical study

\begin{tabular}{|c|c|c|c|c|c|}
\hline \multirow[b]{2}{*}{ Animal } & \multirow[b]{2}{*}{ Sensitizing antigen } & \multicolumn{4}{|c|}{ Reactivity } \\
\hline & & LDL & HDL & Albumin & $\begin{array}{c}\text { Other } \\
\text { proteins }\end{array}$ \\
\hline \multicolumn{6}{|l|}{ Sheep } \\
\hline $\mathrm{S}_{1}$ & HDL (D 1.063-1.21) & + & + & + & - \\
\hline$S_{1 A}^{*}$ & HDL (D 1.063-1.21) & + & + & - & - \\
\hline $\mathrm{S}_{1 \mathrm{AB}}{ }^{*}$ & HDL (D 1.063-1.21) & - & + & - & - \\
\hline $\begin{array}{c}\mathrm{S}_{2} \\
\text { Rabbits }\end{array}$ & HDL (D 1.063-1.21) & + & + & + & + \\
\hline$R_{1}$ & HDL (D 1.063-1.21) & - & + & - & - \\
\hline $\mathbf{R}_{2}$ & HDL (D 1.063-1.21) & + & + & - & - \\
\hline $\mathrm{R}_{2 \mathrm{~B}} *$ & HDL (D 1.063-1.21) & $\frac{1}{2}$ & + & - & - \\
\hline $\mathbf{R}_{3}$ & HDL (D 1.063-1.21) & + & + & + & - \\
\hline $\mathrm{R}_{3 \mathrm{~A}^{*}}$ & HDL (D 1.063-1.21) & + & + & - & - \\
\hline $\mathbf{R}_{4}$ & HDL (D 1.063-1.21) & + & + & + & + \\
\hline $\mathrm{R}_{5}$ & HDL (D 1.063-1.21) & + & \pm & + & \\
\hline $\mathrm{R}_{6}$ & HDL (D 1.063-1.21) & + & \pm & + & \\
\hline $\mathrm{R}_{7}$ & LDL (D 1.019-1.063) & + & $=$ & - & - \\
\hline$R_{8}$ & LDL (D 1.019-1.063) & + & - & - & - \\
\hline \multicolumn{6}{|c|}{ EDL (D 1.018 (.0.00) } \\
\hline $\mathrm{H}_{1} \dagger$ & Whole serum & + & + & + & + \\
\hline $\begin{array}{l}\mathrm{H}_{2} \\
\mathrm{H}_{3}\end{array}$ & Whole serum & $t$ & \pm & + & + \\
\hline & Whole serum & + & \pm & 十 & + \\
\hline
\end{tabular}

* Absorbed with excess albumin (A) or LDL (low density lipoproteins) (B).

$\dagger \mathrm{H}_{1}=$ Pasteur Institute (223-224) antiwhole serum; $\mathrm{H}_{2}=$ Walter Reed Army Hospital (Leddy) antiwhole serum; $\mathrm{H}_{3}=$ Hyland Laboratories antiwhole serum. 


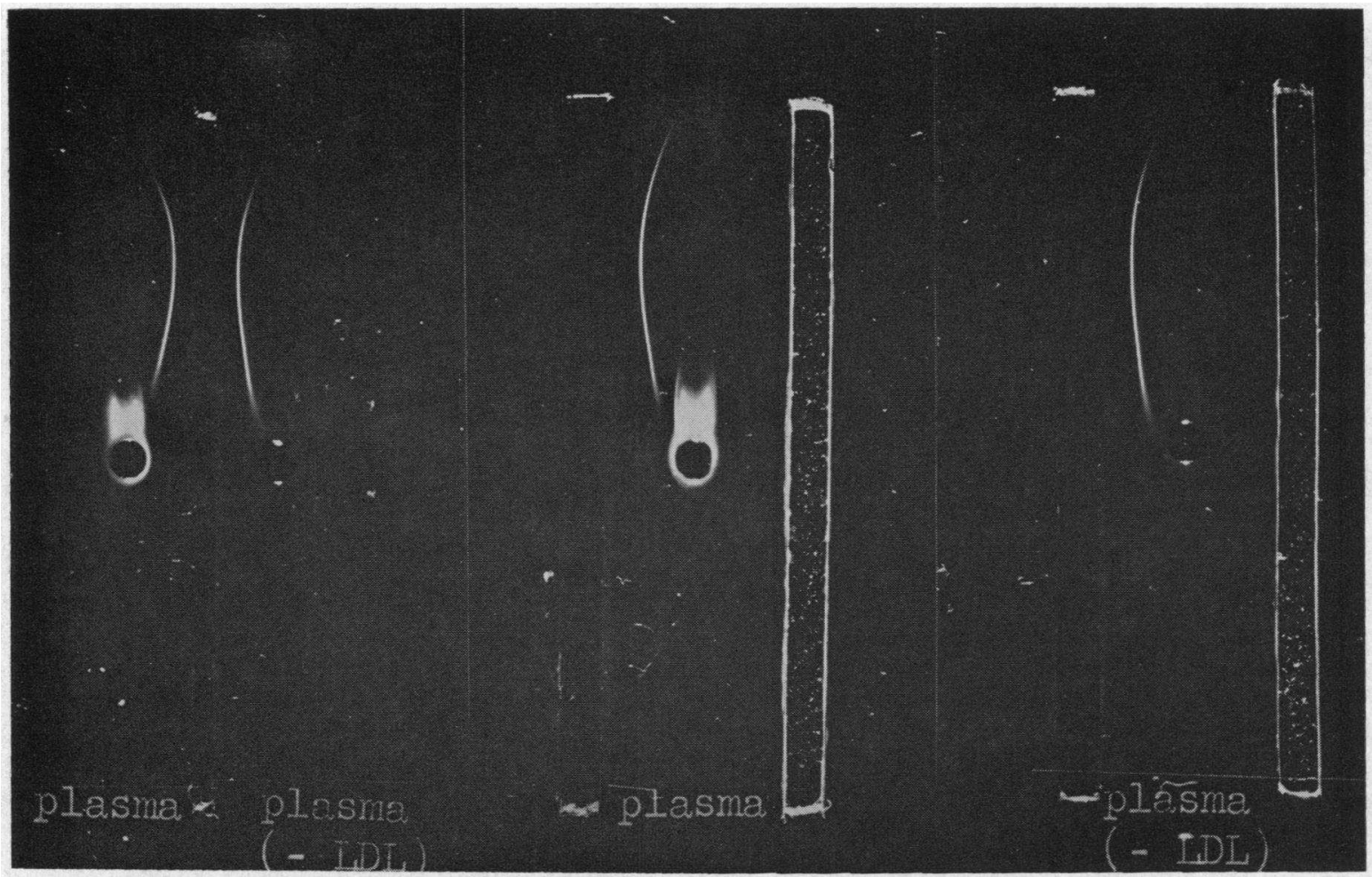

Fig. 2. IMMUNOELECTROPHORESIS OF FRESH PLASMA BEFORE AND AFTER PRECIPITATION OF THE LOW DENSITY LIPOPROTEINS (LDL). In the left hand slide the trough contains antiserum $\mathrm{S}_{1 \mathrm{~A}}$ (Table II); on each of the middle and right hand slides, one trough was filled with antiserum $R_{2}$ and the other with antiserum $R_{7}$ (antiLDL). All precipitation lines on this and succeeding figures are unstained. All the lines shown here were subsequently shown to stain for lipids.

the final dose and the serum frozen after the addition of $0.01 \%$ merthiolate. Each antigen was carefully characterized by immunoelectrophoresis before use. The lipoprotein fractions used as antigen for $S_{1}, S_{2}$, and $R_{1}$ through $R_{6}$ all were derived from pool A (Table I). With each antiserum the precipitating antibodies were shown by immunoelectrophoresis to be almost entirely $\mathrm{G}$ immunoglobulins (7 S globulin) (23). Certain of the antisera were partially purified by sodium sulfate precipitation by the method of Kekwick (24).

Horse antiwhole human serum ${ }^{1}$ and commercial horse antiwhole serum, rabbit anti-beta lipoprotein, and antialbumin ${ }^{2}$ were used.

Characterization of antisera. HDL (density 1.063 to 1.21) used as antigen produced adequate anti-HDL titers in both of two sheep and four of six rabbits. All of the eight antisera are characterized in Table II. Seven cross-reacted with LDL. Several also formed precipitation lines with albumin, and two reacted with other unidentified proteins. Four rabbit and one sheep antisera could be absorbed with albumin or LDL leaving suf-

\footnotetext{
1 Obtained from Walter Reed Army Hospital (Leddy) and the Pasteur Institute (223-224).

2 Purchased from Hyland Laboratories, Los Angeles, Calif.
}

ficient anti-HDL titer for use in the experiments to be described. LDL produced antibodies of relatively higher titer that did not appear to cross-react with HDL or other proteins. Pure HDL antisera were thus very difficult to produce, presumably because the antigen could not be freed of undetected LDL, which is so much stronger in provoking antibody response. Antisera, such as $R_{2}$ (Table II), however, could be freed of all anti-LDL activity by absorption without appreciable decrease in anti-HDL titer.

Hyland antialbumin and anti-LDL were relatively pure. They did not react with HDL fractions and gave sharp precipitation bands with albumin and LDL, respectively. All the antihuman sera contained antibodies to both HDL and LDL. The Pasteur antiserum $\left(\mathrm{H}_{1}\right.$, Table II) gave the sharpest precipitation line with alpha lipoprotein at serum concentration and was used for most experiments with antihuman serum. The other sera were used only to check ultracentrifugal fractions for nonlipoprotein impurities.

Absorption of antibodies was carried out at equivalence as determined by serial dilution using the double diffusion tube method of Preer (25). The precipitates were allowed to stand for 5 to 10 days before absorbed antisera were harvested. 
Agar diffusion. Ouchterlony plates or Preer tubes of $1 \mathrm{~mm}$ i.d. were made with $1 \%$ Difco special noble agar in saline. Plates with wells requiring 5 to $10 \mu \mathrm{l}$ or 40 to $50 \mu \mathrm{l}$ of antigen or antibody were used. They were allowed to develop at $4^{\circ} \mathrm{C}$ and observed for at least 2 weeks. The Preer tubes were sealed after preparation with molten paraffin and allowed to develop at room temperature. The appearance of precipitin bands and their location in relationship to the antigen-agar boundary were plotted daily for 10 days.

Immunoelectrophoresis. The technique of Grabar and Williams (26) as modified for microscope slides by Scheidegger (27) was used for immunoelectrophoresis. Standard microscope slides were coated with a thin film of $2 \%$ Difco special noble agar in 0.05 Veronal buffer, $\mathrm{pH} 8.2$, and allowed to dry. Two $\mathrm{ml}$ of the agar in buffer was then applied in a coat of uniform thickness. To assure uniform water content, plates were always used within 2 hours of preparation. The wells were filled with 2 to $3 \mu$ l of antigen, and electrophoresis was carried out in $0.05 \mathrm{M}$ Veronal buffer at $\mathrm{pH} 8.2$ using constant current (58 ma) for exactly 40 minutes. Proteins were either precipitated immediately after electrophoresis with $2 \%$ acetic acid or allowed to diffuse against 50 to $60 \mu \mathrm{l}$ of antiserum for 24 to 72 hours at room temperature in a high humidity chamber. Slides were then washed overnight with saline, followed by distilled water, dried, and exposed to a freshly prepared saturated solution of oil red $\mathrm{O}$ in $60 \%$ ethanol at $40^{\circ} \mathrm{C}$ for at least 12 hours and then counter- stained for protein with SF light green for 2 hours. Photographs of the immunoprecipitation lines were made before washing, after oil red $\mathrm{O}$ staining, and again after counterstaining.

Protein analyses. Ultracentrifugal fractions of $\mathrm{LDL}$, $\mathrm{HDL}, \mathrm{HDL}_{2}$, and $\mathrm{HDL}_{3}$ were extracted with ethanol: ether (3:1) for 18 to 24 hours at $24^{\circ} \mathrm{C}$ (3). The precipitate was washed twice with ethanol and once with ether. Portions of the precipitate were sealed in an oxygen-free atmosphere and hydrolyzed at $110^{\circ} \mathrm{C}$ for 24 hours in $6 \mathrm{~N} \mathrm{HCl}$. Some of the delipidated proteins were oxidized with performic acid for 1 hour and were then lyophilized before acid hydrolysis (28). Hydrolysates representing 0.5 to $5 \mathrm{mg}$ of protein were analyzed for amino acid content with the Spinco Moore-Stein analyzer. Quantification was standardized using known references (29). Two of the plasma fractions were analyzed four times each, and the amounts of individual amino acids obtained on each run were in agreement within $3 \%$. Amino terminal acids were determined by the dinitrophenol method of Levy (30).

\section{Results}

Heterogeneity of alpha lipoprotein. Immunoelectrophoretic studies. Fresh, whole plasma or plasma from which all low density lipoproteins had been removed by precipitation with polyanions usually yielded on immunoelectrophoresis a single

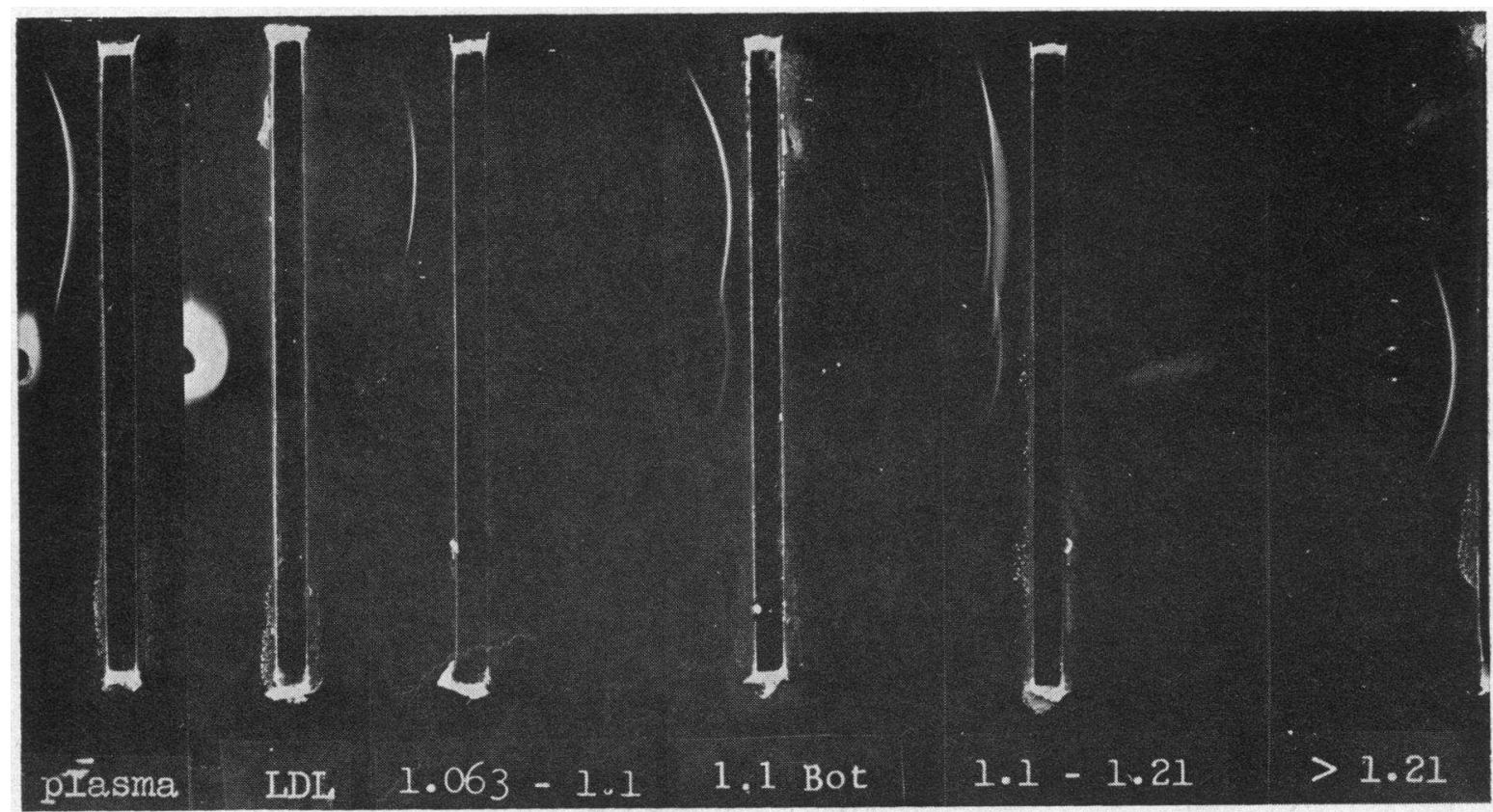

Fig. 3. IMMUNOELECTROPHORETIC PATTER OF PLASMA AND THE ULTRACENTRIfUgal FRACTIONS REACTED With ANTISERA $\mathrm{S}_{1 \mathrm{~A}}$. All fractions except LDL and the 1.1 to $1.21\left(\mathrm{HDL}_{3}\right)$ fraction are at plasma concentration. LDL and the 1.1 to 1.21 fraction represent threefold increases from plasma concentration. All the precipitation lines seen here were subsequently shown to stain for lipid. 




Fig. 4. IMMUNOELECTROPHORETIC PATTERN OF PLASMA AND THE TWO HDL SUBFRACTIONS AFTER PRECIPITATION WITH ANTISERUM $\mathrm{R}_{3 \mathrm{~s}}$. Concentrations of $\mathrm{HDL}_{2}$ and $\mathrm{HDL}_{8}$ are identical to those in the previous figure. All visible precipitation lines were shown to stain for lipid.

precipitation arc attributable to alpha lipoprotein with any of the eight anti-HDL antisera described in Table II (Figure 2). However, under appropriate conditions and especially in certain ultracentrifugal fractions, heterogeneity of the alpha lipoproteins became apparent with all of the antisera. As shown in Figures 3 and 4 a single broad arc with anti-HDL serum was present in fresh whole plasma and in the ultracentrifugal fraction containing $\mathrm{HDL}_{2}$ (density 1.063 to 1.1 ). There was in addition a second band of slower migration in ultracentrifugal fractions of $\mathrm{HDL}$ (density 1.063 to 1.21 ) and $\mathrm{HDL}_{3}$ (density 1.1 to 1.21 ). Only the second band was present in the fraction density $>1.21$.

Both of these precipitation bands were lipid staining, although the second band was occasionally only faintly so. The positions of these bands were relatively constant, the first migrating with and just behind the albumin, the second in the 
alpha $_{1}$-alpha $_{2}$ region. With the antisera, only the first band could be detected in $\mathrm{HDL}_{2}$, but both bands were always detected in $\mathrm{HDL}_{3}$. Only the second band was ever detected in the fraction density $>1.21$. As shown in Figures 3 and 4 and subsequently in Figures 5 and 6 , these arcs blended completely, crossed, or appeared as several interrupted lines depending upon the antiserum used. The precipitation lines obtained with HDL (density 1.1 to 1.21 ) in Figures 3 and 4 represented the extreme in complexity obtained, and these were observed only with two antisera and with concentrations of $\mathrm{HDL}_{3}$ considerably in excess of that in plasma. The small precipitation lines close to the junction of the major bands were interpreted as also representing reactions between antisera and the HDL antigens and not unrelated contaminants. They were not seen when only one or the other major band was present alone as in concentrated preparations of $\mathrm{HDL}_{2}$ or the fraction of density $>1.21$. Furthermore, all the lines stained for lipid, and they were removed by absorption along with the major bands (see below). The multiplicity of lines is considered to reflect the fact that the HDL was composed of very similar but not identical antigens. All of the antigenic preparations used for antibody production contained HDL over the density spectrum from 1.063 to 1.21 . It appears that a family of antibodies was produced, its members differing in reactivity to certain antigenic sites, only some of which were common to HDL throughout its density spectrum. It was concluded that there were only two major antigens in HDL, these being detected with all the antisera.

Recombination and absorption studies. Recombination of the lipoprotein fractions with each other or with plasma (Figure 5) confirmed that

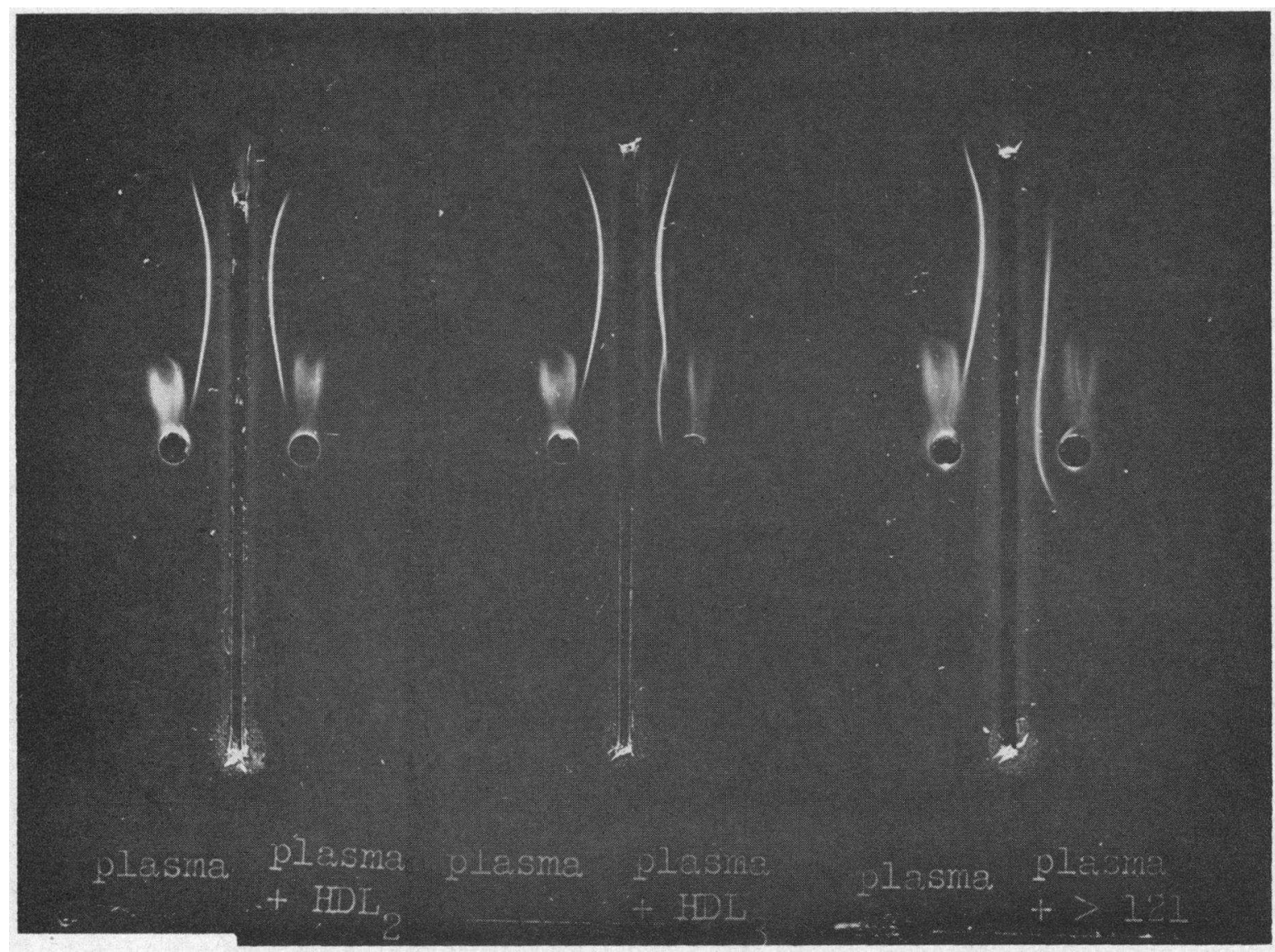

Fig. 5. IMMUNOELECTROPHORESIS OF PLASMA BEFORE AND AFTER ADDITION OF AN EQUAL VOLUME OF A SOLUTION containing either HDL $2, \mathrm{HDL}_{3}$, or the fraction of D $>1.21$ at plasma concentration. Antiserum S was used. All precipitation lines stained subsequently for lipid. 


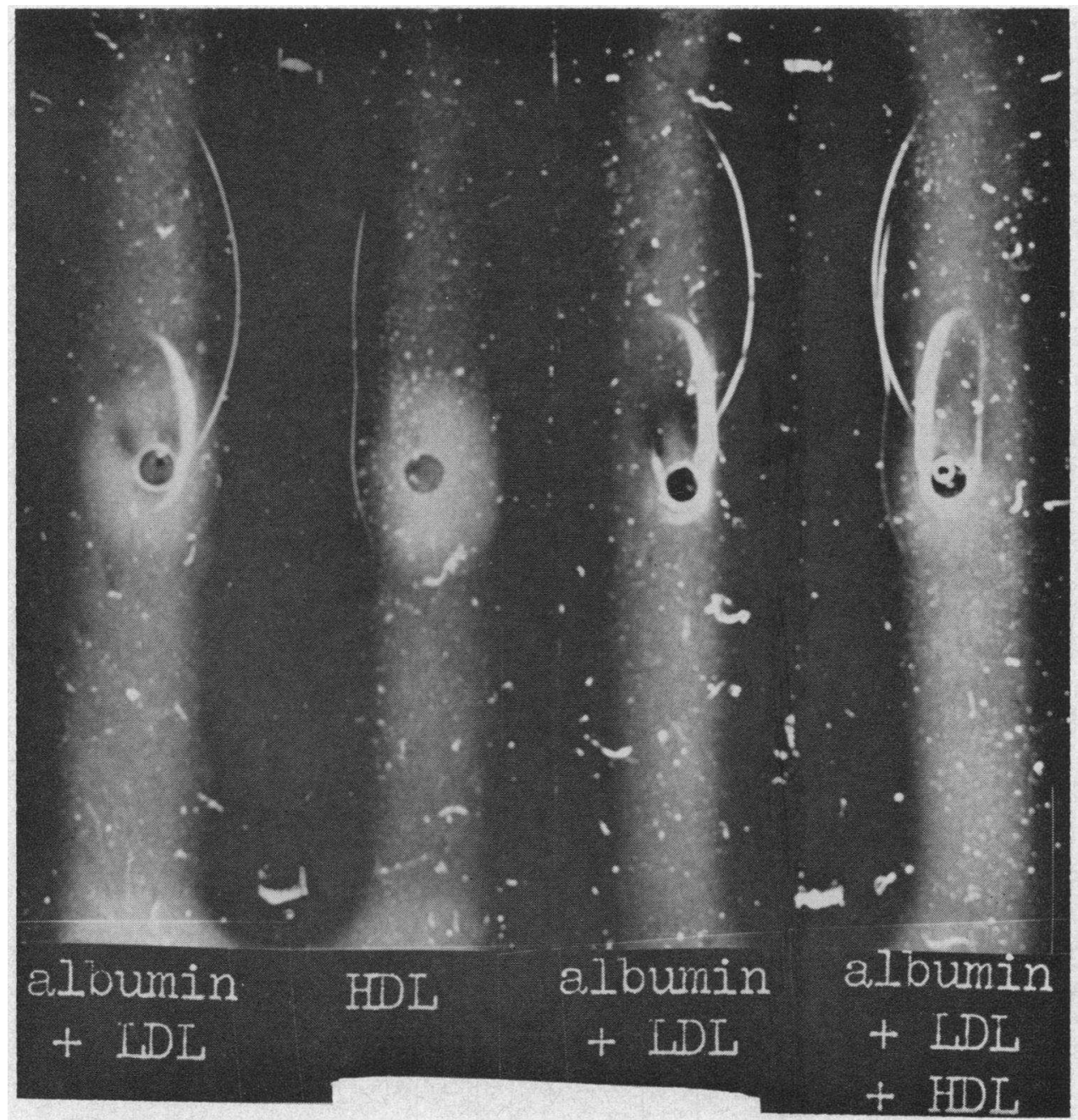

Fig. 6. ImmunoelectrophoRetic pattern of Albumin, LDL, AND HDL with ANTisera H.

the alpha lipoprotein in whole plasma and that in $\mathrm{HDL}_{2}$ was identical, and different from the second more slowly migrating band. By similar combination experiments (Figure 6), it could easily be demonstrated that neither of these bands was related to either albumin or lipoprotein of density 1.019 to 1.063 (LDL).

With Preer tubes (25), the titers of antiserum $\mathrm{S}_{1 \mathrm{AB}}$ to each of the alpha lipoprotein bands were determined separately with a sample of $\mathrm{HDL}_{2}$, containing only the faster migrating band, and a sample of fraction $>1.21$ that contained only the slower migrating band. This antiserum easily discriminated both bands in $\mathrm{HDL}_{3}$. An amount of $\mathrm{HDL}_{2}$ slightly in excess of equivalence was then added to $\mathrm{S}_{1 \mathrm{~A}}$. This absorbed antibody was then tested against whole plasma and several
HDL fractions by immunoprecipitation, doublediffusion, and immunoelectrophoresis. No reactions were now obtained with either plasma or $\mathrm{HDL}_{2}$. Precipitation was obtained with $\mathrm{HDL}_{3}$ and the density $>1.21$ fraction, which proved only to represent the slower migrating band on immunoelectrophoresis.

Similar absorption of antiserum $S_{1 A B}$ with the density $>1.21$ fraction in amounts slightly in excess of equivalence left reactivity to plasma, $\mathrm{HDL}_{2}$, and $\mathrm{HDL}_{3}$. This was shown to represent only the fast migrating band on immunoelectrophoresis. No reaction was obtained with the density $>1.21$ fraction. Quantitatively about two-thirds of the reactivity of antiserum $\mathrm{S}_{1 \mathrm{AB}}$ could be removed with either $\mathrm{HDL}_{2}$ or the $>1.21$ fraction. Results of similar absorption 
experiments using other antisera varied depending on their ability to discriminate between the two forms of alpha lipoprotein.

Nomenclature. On the basis of the above experiments, the two forms of alpha lipoprotein distinguishable by immunoelectrophoresis have been designated as alpha $\mathrm{LP}_{\mathbf{A}}$, the band of greater migration seen in plasma, $\mathrm{HDL}, \mathrm{HDL}_{2}$, or $\mathrm{HDL}_{3}$; and alpha $\mathrm{LP}_{\mathrm{B}}$, the second band present only in $\mathrm{HDL}_{3}$ and the density $>1.21$ fraction (Figure $7)$. This nomenclature incorporates the designa- tion "LP" to differentiate the lipoprotein from the delipidated protein, alpha P. ${ }^{3}$

Diffusion and precipitation studies. Small amounts of alpha $\mathrm{LP}_{\mathbf{B}}$ could be detected in fresh plasma by immunoelectrophoresis if the plasma was concentrated 5- to 10 -fold by polyethylene glycol (15) or triple-loading of the antigen wells.

${ }^{3}$ In a preliminary communication (17), alpha $L P_{B}$ was referred to as alphad, a simpler term, but offering less flexibility for possible new forms of alpha lipoprotein that conceivably may be demonstrated in the future.

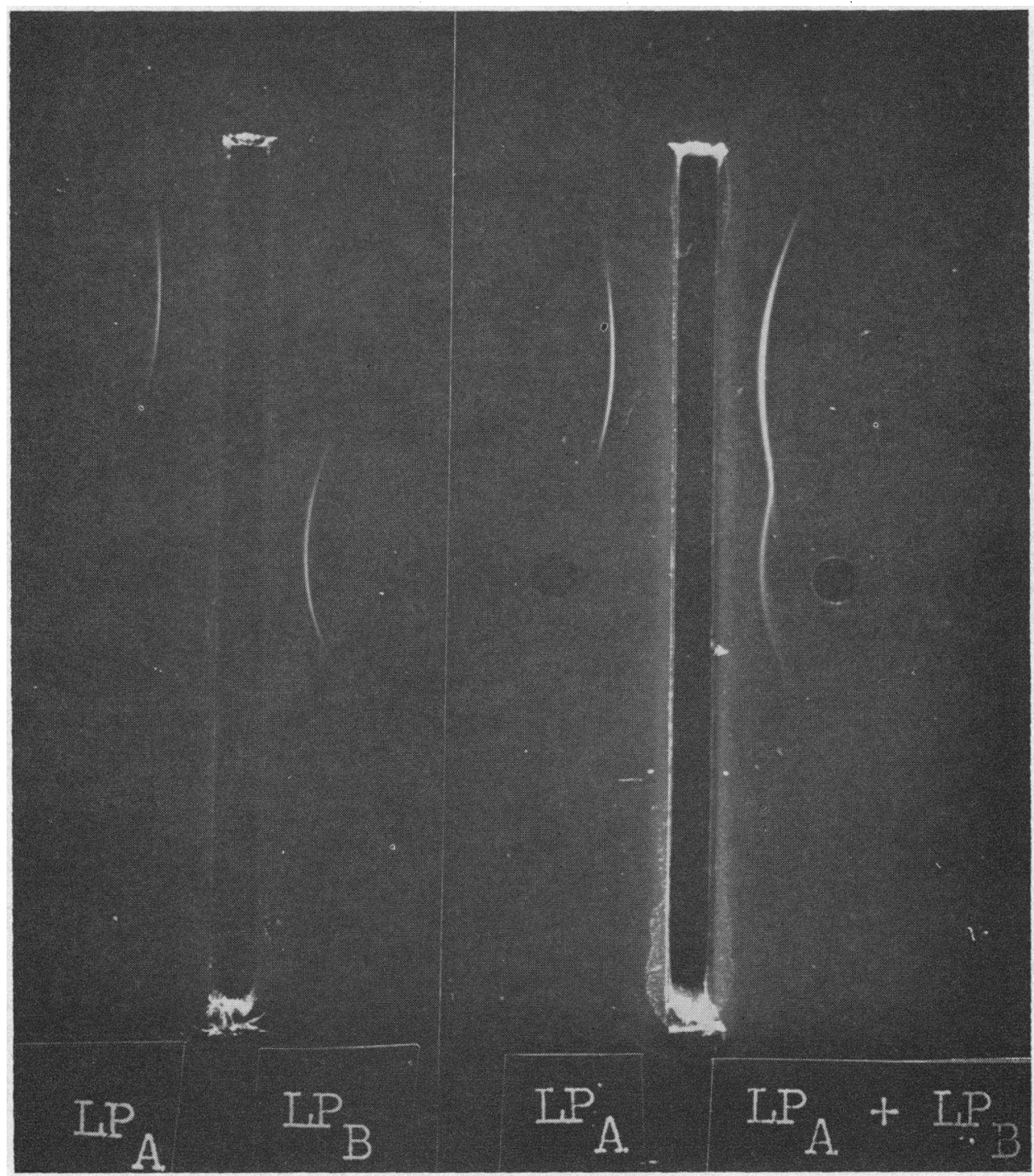

Fig. 7. IMMUNOELECTROPHORETIC PATTERNS OBTAINED WITH ANTISERUM $\mathrm{R}_{1}$ AND LIPOPROTEIN FRACTIONS HDL (D 1.063 TO 1.1) AND DENSITY GREATER THAN 1.21 UNDERGOING ELECTROPHORESis SEPARATEly (LEFT HAND SLIDE) AND IN COMBINATION (RIGHT HAND SLIDE). HDL 2 contains only the form designated alpha $L_{P_{A}}$, and the density greater than 1.21 fraction contains only the form designated alpha $\mathrm{LP}_{\mathbf{B}}$. All the lines shown here stain for lipid. 


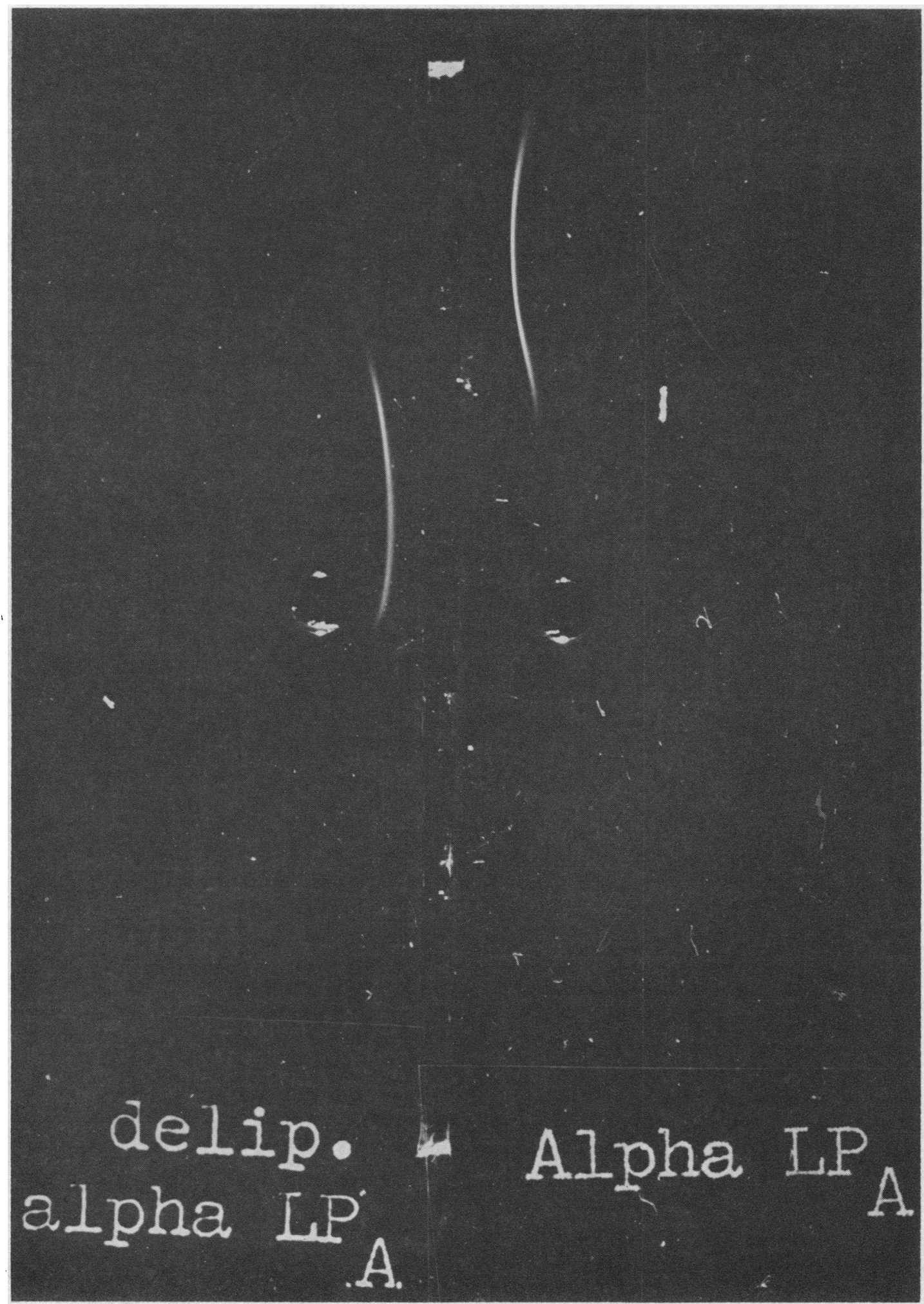

Fig. 8. Immunoelectrophoretic pattern of HDL 2 (alpha LP A $_{\text {) ANd }}$ its partially DELIPIDATED PRODUCT. Antiserum $S_{1 A}$ was used. Both lines shown here stain for lipid. 
Usually very small amounts of this second alpha band could be detected in unconcentrated plasma by Ouchterlony plates or especially by the method of Preer. Even with these more sensitive techniques, only one line was seen with $\mathrm{HDL}_{2}$ using any of the antisera, emphasizing the immunologic homogeneity of this lipoprotein fraction.

With either the Preer or Ouchterlony techniques, repetition of the absorption studies with antiserum $\mathrm{S}_{1 \mathrm{~A}}$, described above, using immunoelectrophoresis, again demonstrated that alpha $\mathrm{LP}_{\mathbf{A}}$ and alpha $\mathrm{LP}_{\mathbf{B}}$ differed in some antigenic sites for this antiserum.

As could be predicted from immunoelectrophoresis, the two forms of alpha lipoprotein could also easily be distinguished by differing mobility on simple electrophoresis on agar.

Conversion of alpha $L P_{A}$ to alpha $L P_{B}$. The absence of significant amounts of alpha $\mathrm{LP}_{B}$ from fresh serum and its obvious appearance in certain of the ultracentrifugal fractions implied that the latter process was capable of producing alpha $\mathrm{LP}_{\mathbf{B}}$, quite probably through the conversion of some of alpha $\mathrm{LP}_{\mathbf{A}}$.

The appearance of alpha $\mathrm{LP}_{\mathrm{B}}$ during ultracentrifugation proved to be dependent upon the exposure of lipoprotein to a centrifugal field and not to the other manipulations attending the routine preparative procedure. Serum brought to a density of 1.063 by addition of $\mathrm{NaCl}-\mathrm{KBr}$, allowed to stand at $15^{\circ} \mathrm{C}$ for 1 week, and then

TABLE III

A mino acid compositions of the proteins of serum $L D L, H D L$, and $H D L$ subfractions*

\begin{tabular}{lrrrr}
\hline \hline & LDL & HDL & HDL & HDL $~$ \\
\hline Aspartic & 100 & 100 & 100 & 100 \\
Threonine & 56 & 58 & 58 & 60 \\
Serine & 74 & 84 & 84 & 81 \\
Glutamic & 118 & 244 & 244 & 239 \\
Proline & 40 & 56 & 59 & 59 \\
Glycine & 45 & 54 & 51 & 52 \\
Alanine & 59 & 93 & 93 & 93 \\
Cystine & & 7 & 7 & 6 \\
Valine & 52 & 68 & 66 & 65 \\
Methionine & 13 & 10 & 12 & 10 \\
Isoleucine & 53 & 7 & 6 & 6 \\
Leucine & 108 & 161 & 159 & 160 \\
Tyrosine & 33 & 39 & 39 & 40 \\
Phenylalanine & 49 & 41 & 41 & 40 \\
& & & & \\
\hline
\end{tabular}

* All values are expressed as moles relative to aspartic acid taken as 100. LDL = D 1.019 to 1.063 .

t Cystine determined as cysteic acid after pretreatment of hydrolysate with performic acid. dialyzed against saline containing $0.01 \mathrm{M}$ EDTA contained no alpha $\mathrm{LP}_{\mathrm{B}}$ detectable by immunoelectrophoresis. In contrast, alpha $\mathrm{LP}_{\mathbf{B}}$ became readily apparent at serum concentration in the infranate after a single 16- to 24-hour centrifugation at density 1.063. Furthermore, repeated centrifugation at density 1.21 of either HDL or $\mathrm{HDL}_{2}$ yielded additional alpha $\mathrm{LP}_{\mathbf{B}}$ in the infranate of each successive run indicating continuous production of this form of the lipoprotein during ultracentrifugation.

Storage, as well as ultracentrifugation, was found to lead to the production of alpha $L P_{B}$. Although fresh serum or plasma obtained with EDTA, sodium oxalate, or heparin as anticoagulant contained little or no detectable alpha $\mathrm{LP}_{\mathrm{B}}$, it became increasingly demonstrable during storage of the unconcentrated samples over a period of 2 to 10 days. Storage of plasma in EDTA minimized the generation of alpha $\mathrm{LP}_{\mathbf{B}}$.

Alpha $\mathrm{LP}_{\mathbf{B}}$ was also produced by repeated freezing and thawing between $4^{\circ}$ and $-20^{\circ} \mathrm{C}$ or by addition of urea to plasma in a final concentration of $8 \mathrm{M}$. As alpha $\mathrm{LP}_{\mathbf{B}}$ became apparent, the titer of alpha $\mathrm{LP}_{\mathbf{A}}$ decreased. As noted earlier, the supernate remaining after removal of LDL by precipitation (18) contained only alpha $\mathrm{LP}_{\mathbf{A}}$ (Figure 2), but the $\mathrm{B}$ form was then easily produced by either simple storage of the supernate without EDTA, or by freezing and thawing. This experiment provided further proof that alpha $\mathrm{LP}_{\mathbf{B}}$ was derived from alpha $\mathrm{LP}_{\mathbf{A}}$ and not from other lipoprotein precursors.

Final proof of the conversion of the $\mathrm{A}$ form to the $\mathrm{B}$ was provided in the following experiment, the results of which are shown in Figure 8. An $\mathrm{HDL}_{2}$ fraction, containing no alpha $\mathrm{LP}_{\mathbf{B}}$, was partially delipidated with ethanol: ether $(3: 1)$ and washed with ether. The resulting material was completely soluble in $0.15 \mathrm{M} \mathrm{NaCl}$. It was subjected again to immunoelectrophoresis and consisted almost exclusively of alpha $\mathrm{LP}_{\mathrm{B}}$. Partial delipidation of the fraction 1.1 to 1.21 , in the same way, again eliminated most of the alpha $\mathrm{LP}_{\mathbf{A}}$ with a concomitant gross increase in the amount of alpha $\mathrm{LP}_{\mathrm{B}}$. The slower migrating material produced by delipidation of alpha $\mathrm{LP}_{\mathbf{A}}$ was recombined with plasma, $\mathrm{HDL}_{2}, \mathrm{HDL}_{3}$, and the fraction density $>1.21$. Both immunoelectrophoresis and double diffusion of these mixtures 
on Ouchterlony plates indicated that the delipidated product was immunochemically identical to alpha $\mathrm{LP}_{\mathrm{B}}$.

Protein analyses. In Table III are presented the relative amino acid compositions of the lipoprotein fractions LDL, $\mathrm{HDL}, \mathrm{HDL}_{2}$, and $\mathrm{HDL}_{3}$. The values given for each fraction represent the means obtained on 3 to 5 separate preparations of each fraction. These, as well as separate determinations on the same fractions, all agreed within $3 \%$. The amino acid compositions of these HDL fractions were indistinguishable and different from those previously published for LDL and albumin $(3,31)$. The basic amino acids, arginine, histidine, and lysine are not shown in Table III. They were determined once on a single sample of each fraction. The contents of these amino acids were indistinguishable in HDL and its fractions. No attempt was made to correct for possible losses of amino acids during hydrolysis, nor was there an attempt to quantify tryptophan or amide ammonia. As previously noted by others $(3,9,11,32)$, the HDL fractions all contained amino terminal aspartic acid with trace amounts of serine and threonine. In view of the similarity of the amino acid analyses of the HDL fractions, the peptides contained in alpha $L P_{\mathbf{A}}$ and $L P_{B}$ are very probably identical. The analyses of HDL amino acids (Table III) are comparable to those previously published except for discrepancies in cystine content $(3,9-11$, 33 ). For the latter our results are in agreement with the data of Shore and Shore (33), who used a titration method for determining sulfhydryl groups, but in disagreement with the data of Scanu and Hughes (3) and Sanbar and Alaupovic (10), which showed little or no cystine. This is probably explained by our pretreatment of protein hydrolysates with performic acid con,verting the cystine and cysteine present to the more stable cysteic acid before acid hydrolysis (28).

\section{Discussion}

Two forms of alpha lipoprotein, designated A and $B$, have been demonstrated. The native state of this lipoprotein in plasma appears to be almost entirely alpha $\mathrm{LP}_{\mathbf{A}}$. As plasma ages, undergoes ultracentrifugation, or is otherwise manipulated, alpha $\mathrm{LP}_{\mathbf{B}}$ appears. It is distinguished from alpha $\mathrm{LP}_{\mathbf{A}}$ by differences in electrophoretic migration, immunochemical behavior, and flotation in the ultracentrifuge. Proof has been presented that alpha $\mathrm{LP}_{\mathbf{B}}$ can be derived from alpha $\mathrm{LP}_{\mathbf{A}}$ by partial delipidation, but there is other evidence that this transformation may involve more than simple loss of lipid.

The importance of these findings lies particularly in three areas: First is the practical problem of having to deal with several forms of alpha lipoprotein in any immunochemical studies of plasma lipoproteins, particularly those aimed at defining the purity of lipoprotein isolates. The second is the implication that use of the ultracentrifuge to isolate and quantify high density lipoproteins is associated with molecular rearrangements that give rise to heterogeneity that probably does not exist in normal plasma. Finally, the observed transformation of alpha lipoprotein correlates with other data relevant to the peptide portions of high density lipoprotein in such a way as to offer further insight into the structure of lipoproteins.

The eight different antisera employed in this study varied in their specificity for the $A$ and $B$ forms of alpha lipoprotein. All, however, when used with immunoelectrophoresis, distinguished these two forms. Most of the antisera showed only partial cross-reactivity with each by either immunoelectrophoresis, double diffusion, or differential absorption. In assessing the validity of these findings it has been necessary to reconsider why, if the differences between alpha $\mathrm{LP}_{\mathbf{A}}$ and alpha $\mathrm{LP}_{\mathbf{B}}$ now seem apparent, has heterogeneity of alpha or high density lipoproteins not been more widely recognized in many previous immunochemical studies of these lipoproteins. In reviewing these in light of the present experiments, it is impressive how much evidence of heterogeneity has actually been present, and how closely it seems to corroborate the present demonstration of more than one form of alpha lipoprotein.

Aladjem, Lieberman, and Gofman (12) made the first immunochemical studies of HDL and concluded that these lipoproteins were not (antigenically) homogeneous. Interestingly, they found evidence of antigenic differences between the centrifugal subfractions $\mathrm{HDL}_{2}$ and $\mathrm{HDL}_{3}$. The only other study employing a specific anti- 
HDL serum was that of DeLalla, Levine, and Brown (5). Although their experiments are often cited as proof of the homogeneity of HDL, their data are actually more consistent with their single antiserum having been primarily reactive with what is now called alpha $\mathrm{LP}_{\mathbf{B}}$. Its titer of reactivity for alpha lipoprotein was much higher with aged plasma, HDL fractions, and the fraction of density $>1.21$ than with comparable amounts of fresh plasma. They also obtained precipitation lines showing only partial identity between plasma and ultracentrifugally isolated HDL fractions in reacting with their antiserum.

Heterogeneity of alpha lipoprotein can also be seen in most published experiments using immunoelectrophoresis with antiwhole human sera. This was recognized by Ayrault-Jarrier, Levy, and Pòlonovski in their work (15), but it also appears to be present in the patterns published by Uriel and Grabar (13) and Grabar and Burtin (14). If one assumes that the absolute migration rates of the three lipid-staining bands obtained by Uriel and Grabar (13) differed from ours due to differences in water content of the agar (34), their "rho-lipoprotein" and "lipalbumin" lines represent alpha $\mathrm{LP}_{\mathbf{A}}$ and $\mathrm{LP}_{\mathbf{B}}$, respectively. Neither line was present in their precipitate of LDL obtained by polyanions, the latter yielding only a single lipoprotein band, which they called "alpha." Burstein and Fine, using a technique that precipitates some of the alpha lipoprotein from material first freed of LDL, have also recently found two precipitation bands (16).

Scanu, Lewis, and Page also obtained two immunoelectrophoretic bands with HDL (4), but attributed one of these to albumin contamination. It is interesting how closely their published patterns resemble those we have obtained with the two forms of alpha lipoprotein.

Today the most widely used techniques for the preparation and quantification of lipoproteins depend upon the ultracentrifuge. Column chromatography has been attempted without demonstrated success (35). Precipitation methods with high molecular weight substances, which quite successfully permit separation of pure low density lipoproteins $(18,36)$, have so far proved capable of isolating only a small fraction of the total alpha lipoprotein in plasma (16). There still is, there- fore, no method for isolating large amounts of high density lipoproteins that does not involve high speed centrifugation at least as a purification step.

The present studies are disturbing in their demonstration that ultracentrifugation is associated with alterations in high density lipoproteins that affect both their structure and quantitative recovery. The native form of $\mathrm{HDL}$, alpha $\mathrm{LP}_{\mathbf{A}}$, is progressively converted to a lipoprotein form of higher density (alpha $\mathrm{LP}_{\mathrm{B}}$ ) with the loss of some to the infranate of the accepted density limit of 1.21. Such losses probably have been responsible in part for the tendency of concentrations of high density lipoproteins to be lower than that of their counterparts isolated by Cohn fractionation and electrophoresis (37). The conversion of alpha $\mathrm{LP}_{\mathbf{A}}$ to alpha $\mathrm{LP}_{\mathbf{B}}$ also probably accounts for much of the great variation in relative concentrations of HDL subfractions reported in the literature $(2,3,7,19,38)$.

The two forms of alpha lipoprotein have been shown to bear a constant relationship to the two peaks into which HDL separates in the analytical ultracentrifuge by the technique of deLalla and associates. $\mathrm{HDL}_{2}$ (density 1.063 to 1.1 ) represents only the A form, whereas $\mathrm{HDL}_{3}$, the fraction of greater density (1.1 to 1.21$)$, contains both $\mathrm{A}$ and $\mathrm{B}$. Theoretically the relative amounts of $\mathrm{HDL}_{2}$ and $\mathrm{HDL}_{3}$ can be expected to vary with the degree of conversion of alpha $\mathrm{A}$ to $\mathrm{B}$. It is interesting in this regard to compare analyses of $\mathrm{HDL}_{2}$ and $\mathrm{HDL}_{3}$ obtained in the analytical ultracentrifuge. Two such studies, in two similar populations with similar total HDL concentrations, have been reported in the past few years from the Donner Laboratory $(7,38)$. The ratios of $\mathrm{HDL}_{2}$ to $\mathrm{HDL}_{3}$ in the two sets of data are very different. There may be other possible explanations for these differences, but the fact remains that conversion of alpha lipoprotein during ultracentrifugation must be taken into account in assessing the significance of HDL subfractions. It is possible that the conventional subfractions, $\mathrm{HDL}_{2}$ and $\mathrm{HDL}_{3}$ (5), may be "artifactual" in the sense of their being more related to the transformability of alpha $\mathrm{LP}_{\mathbf{A}}$ than to any specific metabolic influences.

The nature of the transformation of alpha $\mathrm{LP}_{\mathrm{A}}$ to alpha $\mathrm{LP}_{\mathrm{B}}$ can only be inferred from the pres- 
ent data. B certainly contains relatively less lipid than $\mathrm{A}$, as judged from their comparative flotation characteristics and lipid staining, and as confirmed by lipid analyses before and after conversion of $A$ to $B$ by treatment with ethanol: ether. The density range in which $\mathrm{A}$ and $\mathrm{B}$ are found is broad and overlapping, suggesting that the lipid contents of the $\mathrm{A}$ and $\mathrm{B}$ molecules are both variable and frequently similar. This suggests that other differences also probably exist between these two forms.

A possible difference in the protein component of the two forms of alpha must be considered. As indicated, the amino acid compositions of the polypeptide forms $\mathrm{A}$ and $\mathrm{B}$ are indistinguishable. It may be presumed that differences in their electrophoretic mobility and antigenicity therefore can most likely be due to some change in the structure of the protein of the lipoprotein. From previous work it is possible that such a structural change could be the presence of different multiples of an identical peptide subunit.

Shore (9) has shown that the protein contained in HDL subfractions of density 1.093 and 1.149 had the same amino acid analyses and end groups. The protein in density 1.093 molecules had twice the molecular weight of that in the 1.149 fraction and twice the number of amino terminal groups. $\mathrm{He}$ postulated that the protein in the lighter fraction was a dimer of that in the heavier fraction. Scanu, Lewis, and Bumpus (11) and Sanbar and Alaupovic (10) have found a single protein peak after delipidation of HDL over the entire 1.063 to 1.21 density range. The molecular weight of this protein was calculated to be about 75,000 or comparable to that of the monomer of Shore (9). Sanbar and Alaupovic found that this delipidated protein separated into two peaks on standing. The second peak appeared to be an aggregate of the first and could readily be converted to the first peak in the presence of 1 to $4 \mathrm{M}$ urea or increased $\mathrm{pH}(10)$. More recently Shore and Shore (33) have presented evidence that the delipidated density 1.125 to 1.20 lipoproteins can be chemically divided into identical repeating protein subunits of about $36,000 \mathrm{~mol} \mathrm{wt}$.

The report of Scanu and Hughes (3) that their delipidated protein of $75,000 \mathrm{~mol}$ wt migrated upon electrophoresis more slowly on agar and more rapidly on starch gel than did alpha lipoprotein is consistent with the relative mobilities of alpha $\mathrm{LP}_{\mathrm{B}}$ and $\mathrm{LP}_{\mathrm{A}}$ in these same media.

It is considered that alpha $L P_{B}$ could represent a "monomer" form of alpha lipoprotein and alpha $\mathrm{LP}_{\mathbf{A}}$ a "dimer" or larger aggregate than alpha $\mathrm{LP}_{\mathrm{B}}$. It will be necessary to obtain the molecular weight of the protein in each form before this hypothesis can be proved. How aging and exposure of plasma to a high centrifugal field remove lipid from the lipoprotein and quite possibly transform the polypeptide portion are clearly problems that both need to be solved, and should, in the course of their solution, throw much light on the nature of lipoprotein structure.

The demonstration of partially delipidated alpha lipoprotein (alpha $\mathrm{LP}_{\mathbf{B}}$ ) in the ultracentrifugal fraction of density $>1.21$ is quite consistent with its accounting for some of the phospholipid long known to be in this fraction (19, 39-41). Indeed this phospholipid has been shown by Kunkel and Trautman to migrate with the alpha $_{1}$ globulin on starch block electrophoresis (41). The interesting suggestion has been made that an apoprotein circulates in plasma, at a density of $>1.21$ that can be converted to a lipoprotein by the liver (42). A partially delipidated lipoprotein such as alpha $\mathrm{LP}_{\mathbf{B}}$ could be identical to such a carrier and this possibility will have to be explored.

\section{Summary}

The homogeneity of alpha ${ }_{1}$ or high density lipoprotein (density 1.063 to 1.21 ) (HDL) has been studied by immunochemical techniques in combination with electrophoresis, preparative and analytical ultracentrifugation, and amino acid analysis. Lipoproteins from the following sources have been examined: fresh plasma, plasma aged for a few days at $4^{\circ} \mathrm{C}$, or freeze-thawed repeatedly, delipidated, or exposed to $8 \mathrm{M}$ urea, and ultracentrifugal fractions including HDL (density 1.063 to 1.21 ), $\mathrm{HDL}_{2}$ (density 1.063 to 1.1 ), $\mathrm{HDL}_{3}$ (density 1.1 to 1.21 ), and the fraction of density greater than 1.21 .

With the exception of fresh plasma and $\mathrm{HDL}_{2}$, alpha lipoprotein from all the other sources was reproducibly shown to exist in two forms. These have been designated alpha $\mathrm{LP}_{\mathbf{A}}$ and $\mathrm{LP}_{\mathrm{B}}$. These two forms have differing mobility on agar gel electrophoresis, and 7 of 8 antisera prepared in 
three different animal species have found them to be only partially cross-reactive as antigens.

Only very small amounts of alpha $\mathrm{LP}_{\mathbf{B}}$ were found in fresh plasma, and presumably alpha $\mathrm{LP}_{\mathbf{A}}$ is the native form in which these lipoproteins circulate. Both forms contain protein of the same amino acid composition and amino terminal groups. Alpha $\mathrm{LP}_{\mathrm{B}}$ contains relatively less lipid and is judged to be of a greater average density by its flotation characteristics. Alpha $\mathrm{LP}_{\mathbf{B}}$ was shown to be formed from alpha $\mathrm{LP}_{\mathbf{A}}$ by a partial delipidation.

It is concluded that repeated ultracentrifugation of alpha $\mathrm{LP}_{\mathbf{A}}$ is always associated with its transformation in part to alpha $\mathrm{LP}_{\mathrm{B}}$. It was also demonstrated that the standard high density lipoprotein fractions obtained by ultracentrifugation are consistently related to, and their relative concentrations possibly explained by, this transformation. The $\mathrm{HDL}_{2}$ peak of density 1.063 to 1.1 obtained by Gofman and colleagues in the analytical ultracentrifuge consists solely of $\mathrm{LP}_{\mathbf{A}}$, whereas the $\mathrm{HDL}_{3}$ peak (density 1.1 to 1.21 ) consists of alpha $\mathrm{LP}_{\mathbf{B}}$ plus some alpha $\mathrm{LP}_{\mathbf{A}}$. Alpha $L P_{B}$ is also consistently demonstrated by immunochemical techniques in the fraction of density greater than 1.21 , indicating that at least after ultracentrifugation, some alpha lipoprotein is present in a form of greater density than that usually attributed to the lipoproteins.

The relationship of these findings to earlier discrepancies in studies involving the immunochemistry or quantitation of high density lipoproteins is discussed.

\section{Acknowledgments}

We thank Miss Nanci Briggs and Mr. Armando Sandoval for their technical assistance and Dr. John T. Potts for his helpful suggestions.

\section{References}

1. Fredrickson, D. S. The inheritance of high density lipoprotein deficiency (Tangier disease). J. clin. Invest. 1964, 43, 228.

2. Oncley, J. L. Studies of the normal plasma lipoproteins (separatum). Vox Sang. (Basel) 1960, $5,91$.

3. Scanu, A., and W. L. Hughes. Further characterization of the human serum D 1.063-1.21, $\alpha_{1}$-lipoprotein. J. clin. Invest. 1962, 41, 1681.

4. Scanu, A., L. A. Lewis, and I. H. Page. Studies on the antigenicity of $\beta$ - and $\alpha_{1}$-lipoproteins of human serum. J. exp. Med. 1958, 108, 185.
5. DeLalla, L., L. Levine, and R. K. Brown. Immunologic studies of human high density lipoproteins. J. exp. Med. 1957, 106, 261.

6. DeLalla, O. F., and J. W. Gofman. Ultracentrifugal analysis of serum lipoproteins in Methods of Biochemical Analysis, D. Glick, Ed. New York, Interscience, 1954, vol. 1, p. 459.

7. Gofman, J. W., O. F. deLalla, F. Glazier, N. K. Freeman, F. T. Lindgren, A. V. Nichols, B. Strisower, and A. R. Tamplin. The serum lipoprotein transport system in health, metabolic disorders, atherosclerosis and coronary heart disease. Plasma (Milano) 1954, 2, 413.

8. Hazelwood, R. N. The molecular weights and dimensions of some high-density human serum lipoproteins. J. Amer. chem. Soc. 1958, 80, 2152.

9. Shore, B. C- and N-terminal amino acids of human serum lipoproteins. Arch. Biochem. 1957, 71, 1.

10. Sanbar, S. S., and P. Alaupovic. Effect of urea on behavior of the protein moiety of human-serum $\alpha$-lipoproteins in solution. Biochim. biophys. Acta (Amst.) 1963, 71, 235.

11. Scanu, A., L. A. Lewis, and F. M. Bumpus. Separation and characterization of the protein moiety of human $\alpha_{1}$-lipoprotein. Arch. Biochem. 1958, 74, 390.

12. Aladjem, F., M. Lieberman, and J. W. Gofman. Immunochemical studies on human plasma lipoproteins. J. exp. Med. 1957, 105, 49.

13. Uriel, J., and P. Grabar. Etudes des lipoprotéines sériques par l'électrophorèse in gelose et l'analyse immunoélectrophorétique. Bull. Soc. Chim. biol. (Paris) 1956, 38, 1253.

14. Grabar, P., and P. Burtin. Analyse Immunoélectrophorétique des Applications aux Liquides Biologiques Humains. Paris, Masson, 1960, p. 146.

15. Ayrault-Jarrier, M., G. Levy, and J. Polonovski. Etude des $\alpha$-lipoprotéines sériques humaines par immunoélectrophorèse. Bull. Soc. Chim. biol. (Paris) 1963, 45, 703.

16. Burstein, M., and J. M. Fine. Isolement d'une fraction des $\alpha_{1}$-lipoprotéines sériques après précipitation par le sulfate de dextrane en présence des cations bivalents et de saccharose. Rev. franç. Etud. clin. biol. 1964, 9, 105.

17. Levy, R. I., and D. S. Fredrickson. Antigenic heterogeneity of human plasma high density lipoprotein (abstract). J. clin. Invest. 1964, 43, 1286.

18. Burstein, M., and J. Samaille. Sur un dosage rapide du cholesterol lié aux $\alpha$ - et $\beta$ - lipoprotéines du serum. Clin. chim. Acta 1960, 5, 609.

19. Havel, R. J., H. A. Eder, and J. H. Bragdon. The distribution and chemical composition of ultracentrifugally separated lipoproteins in human serum. J. clin. Invest. 1955, 34, 1345.

20. Sperry, W. M., and M. Webb. A revision of the Schoenheimer-Sperry method for cholesterol determination. J. biol. Chem. 1950, 187, 97.

21. Stewart, C. P., and E. B. Hendry. The phospholipins of blood. Biochem. J. 1935, 29, 1683. 
22. Lowry, O. H., N. J. Rosebrough, A. L. Farr, and R. T. Randall. Measurement of protein with the Folin phenol reagent. J. biol. Chem. 1951, 193, 265.

23. Nomenclature for human immunoglobulins. Bull. Wld Hlth Org. 1964, 30, 447.

24. Kekwick, R. A. The serum proteins in multiple myelomatosis. Biochem. J. 1940, 34, 1248.

25. Preer, J. R., Jr. A quantitative study of a technique of double diffusion in agar. J. Immunol. 1956, 77, 52.

26. Grabar, P., and C. A. Williams. Méthode immunoélectrophorétique d'analyse de mélanges de substances antigéniques. Biochim. biophys. Acta (Amst.) 1955, 17, 67.

27. Scheidegger, J. J. Une micro-méthode de l'immunoélectrophorèse. Int. Arch. Allergy 1955, 7, 103.

28. Schram, E., S. Moore, and E. J. Bigwood. Chromatographic determination of cystine as cysteic acid. Biochem. J. 1954, 57, 33.

29. Moore, S., D. H. Spackman, and W. H. Stein. Chromatography of amino acids on sulfonated polystyrene resins. An improved system. Analyt. Chem. 1958, 30, 1185.

30. Levy, A. L. A paper chromatographic method for the quantitative estimation of amino-acids. Nature (Lond.) 1954, 174, 126.

31. Tristram, C. R., and R. H. Smith. Amino acid composition of certain proteins in The Proteins, H. Neurath, Ed. New York, Academic Press, 1963, vol. 1, p. 45.

32. Rodbell, M. N-Terminal amino acid and lipid composition of lipoproteins from chyle and plasma. Science 1958, 127, 701.
33. Shore, V., and B. Shore. The protein subunit of human serum lipoproteins of density 1.125-1.200 $\mathrm{gram} / \mathrm{ml}$. Biochem. biophys. Res. Commun. 1962, 9, 455.

34. Wieme, R. Studies on Agar Gel Electrophoresis: Techniques, Applications. Brussels, Arscia Uitgaven, 1959.

35. Carlson, L. A. Chromatographic separation of serum lipoproteins on glass powder columns. Description of the method and some applications. Clin. chim. Acta 1960, 5, 528.

36. Burstein, M., and J. Samaille. Nouvelle méthode de séparation et de dosage des lipoprotéines de faible densité. Ann. Biol. clin. 1959, 1-2.

37. Eder, H. A. The lipoproteins of human serum. Amer. J. Med. 1957, 23, 269.

38. Lindgren, F. T., and A. V. Nichols. Structure and function of human serum lipoproteins, in The Plasma Proteins, F. W. Putnam, Ed. New York, Academic Press, 1960, vol. 2, p. 1.

39. Bragdon, J. H., R. J. Havel, and E. Boyle. Human serum lipoproteins. I. Chemical composition of four fractions. J. Lab. clin. Med. 1956, 48, 36.

40. Phillips, G. B. Lipid composition of human serum lipoprotein fraction with density greater than 1.210. Proc. Soc. exp. Biol. (N. Y.) 1959, 100, 19.

41. Kunkel, H. C., and R. Trautman. The $\alpha_{2}$ lipoproteins of human serum correlation of ultracentrifugal and electrophoretic properties. J. clin. Invest. 1956, 35, 641.

42. Eder, H. A., P. S. Roheim, and S. Switzer. An apoprotein of the plasma lipoproteins. Trans. Ass. Amer. Phycns 1964, 77, 259. 